\title{
Psychosocial Predictors of Cannabis Use in Adolescents at Risk
}

\author{
Gebhard Hüsler , ${ }^{1,3}$ Bernard Plancherel, ${ }^{2}$ and Egon Werlen ${ }^{1}$
}

Published online: 27 July 2005

\begin{abstract}
This research has tested a social disintegration model in conjunction with risk and protection factors that have the power to differentiate relative, weighted interactions among variables in different socially disintegrated groups. The model was tested in a cross-sectional sample of 1082 at-risk youth in Switzerland. Structural equation analyses show significant differences between the social disintegration (low, moderate, high) groups and gender, indicating that the model works differently for groups and for gender. For the highly disintegrated adolescents results clearly show that the risk factors (negative mood, peer network, delinquency) are more important than the protective factors (family relations, secure sense of self). Family relations lose all protective value against negative peer influence, but personal variables, such as secure self, gain protective power.
\end{abstract}

KEY WORDS: social disintegration model (SDM); adolescents at risk; protective; risk factors; cannabis use.

\section{INTRODUCTION}

Cannabis use is increasing in developed countries; in some parts of the world, cannabis use (at least experimental use) might already be considered a normative life-event for adolescents and young adults: $40-50 \%$ of the population (USA, UK, Germany) or even more (New Zealand) have used the drug. In Switzerland, a study by the ISPA (2001) found that in the age group 14-15-years old, $19.3 \%$ of girls and $27.3 \%$ of boys had smoked cannabis at least once. Keller et al. (2002)present a lifetime prevalence of $38 \%$ for adolescents in Switzerland. Recent research enumerates a confusing range of variables that predict initiation or frequency of cannabis use for adolescents and young adults. Similarly, there are a number of schemes that classify the variables stud-

\footnotetext{
${ }^{1}$ Center of Rehabilitation and Health Psychology Research, University of Fribourg, rte Englisberg 7, CH 1764, Granges-Paccot, Switzerland.

${ }^{2}$ Service Universitaire de Psychiatrie de l'Enfant et de l'Adolescent, Bugnon 25a, CH 1005, Lausanne, Switzerland.

${ }^{3}$ Correspondence should be directed to Gebhard Hüsler, Center for Rehabilitation and Health Psychology Research, University of Fribourg, rte Englisberg 7, 1763, Granges-Paccot, Switzerland; e-mail: gebhard.huesler@unifr.ch.
}

ied. Whilemost schemes include both intrapersonal and interpersonal factors, some include biological variables and some also socio-environmental/social structure variables. In a 4-year prospective examination of risk factors in a community sample of adolescents and young adults, von Sydow et al. (2002) show that different factors predict the onset or severity of cannabis use and progression to abuse and dependence. To summarize, we can classify variables which are important for substance use, especially for cannabis use, as follows (a) Socio-environmental variables (e.g. male gender, low socio-economic status in childhood, adverse life events); (b) Substancerelated variables (e.g. tobacco use, alcohol use, alcohol use disorder, attitudes toward drug use, drug use opportunities, use by peers of nicotine(cannabis); (c) Intrapersonal variables (personality, psychopathology, childhood factors); and (d) Interpersonal variables (the current family, childhood family situation).

\section{Socio-Environmental Variables}

A number of socio-environmental variables have been identified with cannabis use. Both initiation and course of substance use have been related 
to male gender (Poikolainen et al., 2001; McCuller et al., 2001). According to Sobeck et al. (2000) prior substance users were more likely to be males. Concerning the family, living in a single-parent home, and lower socio-economic status have both been associated with adolescent drug use (McCuller et al., 2001).

\section{Substance-Related Variables}

With reference to peer and friend relationships, Andrews et al. (2002) have shown that peer use predicted cigarette use, binge drinking and problem substance use by young adults. Friedman et al. (2000), referring to data from a longitudinal study, have shown that social behavior and peer relationship problems had a more important impact on substance use than did family problems. Ellickson et al. (2004) identified 4 different groups for cannabis consumption: early high users, who decreased from a relatively high level of use at age 13 to a more moderate level; stable light users, who maintained a low level of use; steady increasers, who consistently increased use; and occasional light users, who began use at age 14 and used at low levels thereafter. Controlling for socioeconomic and health outcomes at age 29 revealed that abstainers consistently had the most favorable outcomes. Kashdan et al. (2005) findings support differential pathways from personality to substance use, and gender appears to be an important moderating factor. Negative affectivity was related to greater illicit substance use (cannabis), but not alcohol use or smoking.

\section{Intrapersonal Variables}

Several studies on general populations have shown co-morbidity between depressive mood and substance use (Brown et al., 1996; Fergusson et al., 1996; Michel et al., 1998; Brook et al., 1998). According to Henry et al. (1993), depressive mood preceded substance use at the age of 15 , but only in boys. However, an epidemiological study on a very large number of adolescents has shown that substance use preceded depressive mood (Burke et al., 1994). Trait anxiety and anxiety sensitivity were found to be important personality risk factors for substance use (Comeau et al., 2001).

Interpersonal Variables

Social relationships provide protective effects with respect to substance use: for low-risk subjects, peer social activity may tend to increase substance use because adolescents are exposed to more examples of smoking or alcohol use (Wills et al., 1994). According to Wills and Vaughan (1989), adolescents who find good social support among their peers but low family social support are at increased risk of substance use.

\section{Theoretical Model}

Society-specific variables are said to influence the meaning (and therefore attitudes and use) of cannabis and other substances (Petraitis et al., 1995). Thus social structure is an important contextual variable for targeting secondary prevention in Switzerland and elsewhere. How does a young person's level of disintegration into social structure influence variables related to cannabis use? Two different conceptual frameworks reflect two quite different but equally important theoretical underpinnings in secondary prevention practice: these are (1) developmental and (2) ecological. Developmental psychologists are concerned with the timing of onset and the progression of disorder in the natural course of individual development (Hawkins and Weis, 1985). Social ecologists, in contrast, are concerned with the surrounding layers of social context that support or fail to support, healthy development. From the developmental perspective, there are likely to be optimum methods and optimum timing for taking preventive action, an area that will eventually become clearer as further prevention studies are evaluated longitudinally. Most researchers believe that the developing organism is strongly influenced by context; they therefore use an ecological model, like that of Szapocznik and Coatsworth (1999).

\section{A Social Disintegration Model (SDM)}

This paper proposes a model of progressive risk for cannabis use problems based on SDM. Social disintegration creates vulnerability for cannabis use and abuse, at least in contemporary Western European and North American societies. We therefore propose a restricted model for cannabis consumption, which takes account of social risk factors (sociodemographic variables), intrapersonal variables that is secure self (self-esteem and self-efficacy) and negative mood (depression and anxiety), interpersonal variables such as family relationships (emotional bonding and cohesion) and peer network (delinquent 
peers and substance-using peers), delinquency and cannabis use.

We test the following hypotheses: (a) Basic social disintegration levels are important indicators for inter- and intrapersonal risk variables. This means social disintegration factors partly determine interpersonal and intrapersonal factors, (b) Social disintegration is inversely related to resources and directly related to other non social-disintegration factors, and (c) The interrelated variables of the model only have predictive power for cannabis use when the social disintegration level is controlled.

\section{METHODS}

\section{Participants}

The participants in this study are part of a larger, national, secondary preventive intervention study in Switzerland for adolescents at risk (supra-f). The program targets youth aged 11-20. Criteria for inclusion in the program are one or more of the following: (1) substance use, (2) deviant behavior, (3) school absenteeism or dropping out of vocational training, (4) family problems, and (5) psychological problems. supra- $f$ youth are provided with a range of services such as academic tutoring and supervised recreation (Hüsler et al., 2005). The total number of subjects is 1082. The demographic variables that are significant for the predictions include age, gender and family constellation. There are nearly twice as many boys as girls (731:351), and more older teens than younger ones (607:475). Data presented here are cross sectional at entry to the study before any intervention occurred (see Table 1).

Most youth lived with both parents $(N=611)$, while 230 lived with one parent, 52 lived with people other than their parents, and 27 lived alone (Missing data on living arrangements, 162).

\section{Measures}

Questionnaires can be classified as: (1) sociodemographic data (age, gender, family situation,

Table 1 Age by Gender Groups

\begin{tabular}{ccccc}
\hline Age & Male & $\%$ & Female & $\%$ \\
\hline $11-15$ & 339 & 31.33 & 136 & 12.56 \\
$16-20$ & 392 & 36.22 & 215 & 18.87 \\
& 731 & 67.56 & 351 & 31.44 \\
\hline
\end{tabular}

school background), (2) psychological data (wellbeing: depression, anxiety, (3) relationship with parents (emotional, cohesion), (4) self-efficacy and selfesteem, (5) drug use, and (6) peer network. The psychological data included depression, a 15 item questionnaire with a five point Likert scale (item example: "I was sad," scale: "rarely or not at all-less than one day weekly" to "mostly - 5 to 7 days weekly"; Hautzinger and Bailer, 1993), anxiety, (Laux et al., 1981), measures of self-image (example: "I am sure that I do the right things"; Harter, 1982), self-efficacy (example: "Whatever happens I will cope with it"; Jerusalem and Schwarzer, 1999), relationship with parents (example: "My parents accept me as I am"; Armsden and Greenberg, 1987). For delinquent behavior (Loeber et al., 1989) we used a 13-item scale (yes, no). We measured substance use including cigarette smoking ("never" to "more than 20 daily"), alcohol ("never" to "every day") and cannabis use ("never" to "every day") for the last 30 days (Arènes et al., 1998; Narring et al., 1994). Reliability and validity data can be found in the works cited.

\section{Procedure}

Data were obtained through a self-report questionnaire and interview administered to adolescents in centers for adolescents. The questionnaire took about $45 \mathrm{~min}$ to administer, the interview about $18 \mathrm{~min}$. The staff could be asked for help in case of need (e.g. not understanding the sense of a question). The survey was administered under conditions of confidentiality. The majority of the data was collected not by interview, but by computer. Using a computer rather than an interview improves the validity of data (Supple et al., 1999).

\section{A Psychosocial Model of Adolescent Risk and Protection}

The study uses a structural equation model (SEM) as the main method of analysis. The proposed model includes 4 latent variables derived from our examination of the literature, and consistent with our approach. Latent individual variables include secure self (Secure self $=$ self-efficacy, Factor loading (FL) 0.90 and self-esteem, FL 0.76) and negative mood (Negative $\operatorname{mood}=$ anxiety, FL 0.88 and depression, FL 0.91). Latent social variables include parentchild relationship (Family relations $=$ emotional 


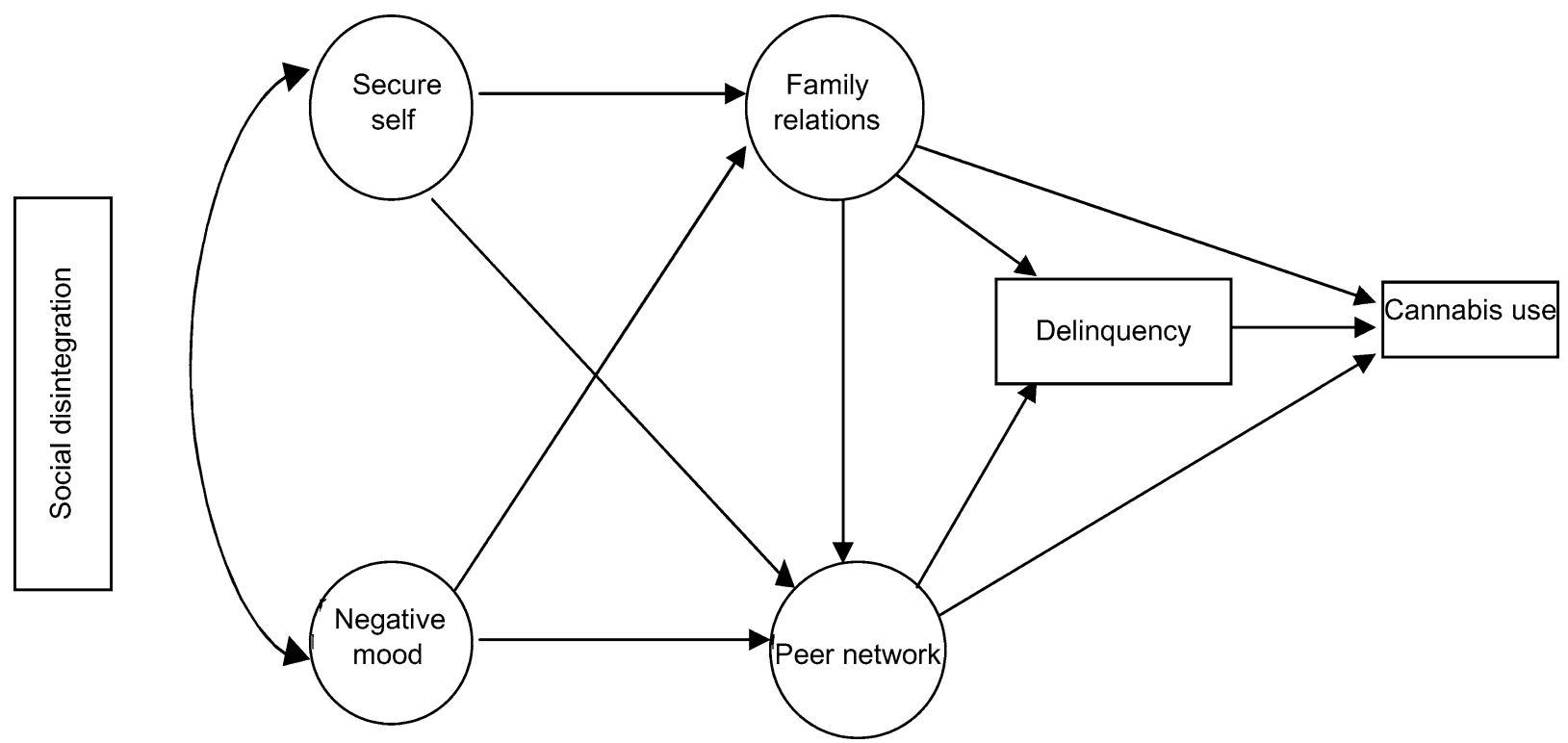

Fig. 1. Social disintegration model (SDM).

attachment to family, FL 0.82 and family cohesion, FL 0.88) and salient peer network (Peer net $=$ delinquent, FL 0.88 , and substance using peers, FL 0.87). Cannabis as the predicted variable covers use in the last 30 days. The non normal distribution of the variable $(1=$ never, $N=576,53.2 \%) ;(2=1-2$ times, $N=156,14.4 \%) ;(3=3-9$ times, $N=84$, $7.8 \%)$; $(4=\geq 9$ times, $N=70,6.5 \%)$ : $(5=$ every day, $N=165,15.2 \%)$ may have an influence on the test of goodness of fit (inflation of chi-square values). But SEM parameters estimates are still fairly accurate according to simulation studies (Kline, 1998, 209).

The level of social disintegration is not part of the structural equation model, but serves as the moderator variable. It classifies the sample (low, moderate, high disintegration). SDM level is constructed by ranking scores on socio-biographical items such as: living with parents, separation of parents, number of moves, number of school year repetitions, number of school drop outs, number of institutions completed. The variable is normally distributed. The classification into three different SDM groups should lead to three different models in which the latent variables have different predictive power (Fig. 1). In previous research we found (Hüsler et al., 2004) that protection and risk factors differ by age and gender.

Our general model predicts both direct and indirect relationships among the risk and protective factors. It predicts that peer relationships and parental relationships have a direct influence on cannabis use.
In addition, the model predicts that a secure self and negative mood each directly influence both family and peer relations, and hence have an indirect influence on the risk of and protection from cannabis use. The general model affords the possibility of illuminating gender and age differences in the interaction of salient variables by level of social disintegration, as well as isolating important interactions for particular groups (See Table 2).

\section{Statistical Analysis}

The model was tested with AMOS.4 (Arbuckle $\&$ Wothke, 1995). The multi-group analysis is used

Table 2 Social Disintegration by Age and Gender

\begin{tabular}{|c|c|c|c|c|c|c|}
\hline & \multicolumn{6}{|c|}{ Social disintegration } \\
\hline & $\begin{array}{c}\text { Age } \\
11-15\end{array}$ & $\%$ & $\begin{array}{c}\text { Age } \\
16-20\end{array}$ & $\%$ & $\begin{array}{c}\text { Age } \\
11-20\end{array}$ & $\%$ \\
\hline \multicolumn{7}{|l|}{ Male } \\
\hline Low & 158 & 46.6 & 149 & 38.0 & 307 & 42.0 \\
\hline Moderate & 119 & 35.1 & 128 & 32.7 & 247 & 33.8 \\
\hline High & 62 & 18.3 & 115 & 29.3 & 177 & 24.2 \\
\hline \multicolumn{7}{|l|}{ Female } \\
\hline Low & 66 & 48.5 & 83 & 38.6 & 149 & 42.5 \\
\hline Moderate & 45 & 33.1 & 65 & 30.2 & 110 & 31.3 \\
\hline High & 25 & 18.4 & 67 & 31.2 & 92 & 26.2 \\
\hline All & 475 & & 607 & & 1082 & \\
\hline
\end{tabular}


Table 3 Social Disintegration Correlated with Variables in Question

\begin{tabular}{|c|c|c|c|c|c|c|c|c|c|c|c|c|}
\hline & 1 & 2 & 3 & 4 & 5 & 6 & 7 & 8 & 9 & 10 & 11 & 12 \\
\hline 2 & .78 & & & & & & & & & & & \\
\hline 3 & -.30 & -.34 & & & & & & & & & & \\
\hline 4 & -.41 & -.50 & .55 & & & & & & & & & \\
\hline 5 & .22 & .25 & -.10 & -.19 & & & & & & & & \\
\hline 6 & .23 & .23 & -.09 & -.15 & .60 & & & & & & & \\
\hline 7 & -.34 & -.37 & .25 & .32 & -.28 & -.19 & & & & & & \\
\hline 8 & -.20 & -.24 & .29 & .26 & -.16 & -.12 & .58 & & & & & \\
\hline 9 & .14 & .15 & -.06 & -.08 & .38 & .37 & -.25 & -.14 & & & & \\
\hline 10 & .13 & .16 & -.10 & -.18 & .52 & .41 & -.26 & -.17 & .46 & & & \\
\hline 11 & .11 & .12 & -.02 & -.02 & .27 & .18 & -.15 & -.06 & .05 & .25 & & \\
\hline 12 & .32 & .30 & -.14 & -.21 & .12 & .04 & -.22 & -.11 & -.18 & -.05 & .05 & \\
\hline 13 & .10 & .10 & -.03 & -.06 & .17 & .14 & -.14 & -.10 & .22 & .23 & .17 & .01 \\
\hline
\end{tabular}

Note. 1: depression, 2: anxiety, 3: self-efficacy, 4: self-esteem, 5: substance using peers, 6: delinquent peers, 7: emotional relation to parents, 8: cohesion to parents, 9: delinquency, 10: cannabis use, 11: age, 12: gender, 13: social disintegration. All correlations $\geq .06$ are significant at $p=.05$

to determine if the same SEM model is applicable across groups. The general procedure is to test for loadings or path invariance between the unconstrained model for all groups combined, then for a model where certain parameters (in this case the path coefficients) are constrained to be equal between the groups. If the chi-square difference statistic does not reveal a significant difference between the original and the constrained-equal models, then the researcher concludes that the model applies across groups. One inference is that there is a moderating effect on causal relationships in the model, and this effect varies by group. We calculated measurement invariance in an earlier step. The result was a nonsignificant chi-square difference $\left(\Delta \chi^{2}=3, d l=4\right.$, $p=.55$ ), indicating that the factor loadings do not differ across groups.

\section{RESULTS}

Social disintegration and the variables in question are only weakly correlated (see Table 3). Negative mood and secure-self are only marginally correlated with social disintegration. But peer network, cannabis use, and delinquency are correlated with social disintegration. Family relations are, predictably, inversely correlated with level of social disintegration, indicating that among more disintegrated youths the relationship with parents is perceived as poor. Older youth are more disintegrated than younger youth. Gender is not related to social disintegration level.

Multi group analyses (see Table 4) indicate that there is a significant difference between groups (low, moderate, high disintegration) and gender. Even if the variance explained by the model is rather modest $(22 \%)$ due to the large sample size, the indices presented in Table 4 indicate it as well fitted.

Disintegration in connection with protective (secure self, relations) and risk factors (negative mood, peer network) leads to differences among the three social disintegration groups (see Table 5). In the low disintegration group the main result is that emotional and cohesive family relations are more protective against negative peers and delinquency, and therefore protect low SDM youth from cannabis use. In the moderately disintegrated group family relations are less powerful in protecting youth against peer network influence, delinquency and therefore cannabis use. Here risk factors are more powerful predictors of cannabis use. For the highly disintegrated adolescents results clearly show that the risk factors (negative mood, peer net, delinquency) are more important than the protective factors. Family relations lose all protective power although personal variables, such as a secure self, gain protective power against negative peer influence. In sum, we note that, as social disintegration risk factors gain importance, protective factors lose their ability to protect.

\section{DISCUSSION}

One general and important finding is that SDM varies with negative mood and cannabis use. That is, high SDM boys and girls score higher on negative mood and substance use. This suggests that risk and protective factors may have a different function in these groups and their effects on prevention may 
Table 4 Structural Equation Analyses: Standardized Maximum Likelihood Estimates for the Free Model and the Constrained Model (equal regression weights for all sub samples)

\begin{tabular}{|c|c|c|c|c|c|c|c|c|c|c|}
\hline Model & $\chi^{2}$ & $d f$ & RMSEA & NFI & CFI & IFI & Comparisons & $\Delta \chi^{2}$ & $d f$ & $p$ \\
\hline \multicolumn{11}{|c|}{ Disintegration } \\
\hline Mf & 215,9 & 78 & .041 & .99 & .99 & .99 & & & & \\
\hline $\mathrm{Mc}$ & 250,6 & 100 & .037 & .99 & .99 & .99 & Mc-Mf & 34,7 & 22 & .04 \\
\hline \multicolumn{11}{|c|}{ Gender } \\
\hline Mf & 177,05 & 52 & .046 & .99 & .99 & .99 & & & & \\
\hline $\mathrm{Mc}$ & 199,55 & 63 & .043 & .99 & .99 & .99 & Mc-Mf & 22,49 & 11 & .02 \\
\hline
\end{tabular}

Note. RMSEA: root-mean-square error of approximation: NFI: normed fit index; CFI: comparative fit index; IFI: incremental fit index; $\Delta \chi^{2}$ : chi-square difference; Mf: Model all parameters free; Mc: equal regression weights for all sub samples.

also be different for boys and girls. In addition it confirms suggestions from Macleod et al. (2004) that psychosocial problems might be more a cause than a consequence of cannabis use, especially with regard to associations between use and mental illness. In accordance with previous research (Swaim et al., 1998; SAMHSA, 1999), rates of delinquent and substance using peers accounted for the greatest variance in cannabis use independent of SDM. However in the current study the role of a delinquent and substance using peer network in the cannabis use trajectory varied by social risk group and gender.

Together with risk and protection factors this model is important for designing and targeting prevention projects. As we have shown, interactions between parents, peers, negative mood and secure self together create different risk and protection patterns for girls and boys from different social backgrounds. In low disintegration boys and girls the SDM gives protective factors against cannabis consumption. Probably this is the case for experimental cannabis use, which is almost normative. As a result, convincing models to predict cannabis use cannot be identified, as our final model for the low risk group has shown. However, with increasing disintegration the SDM gains power for cannabis prediction. For this reason we may consider social disintegration a risk factor for long-term cannabis use. Only the interaction of 'social risk group' and 'high negative mood' leads to regular damaging cannabis use, because the known protective factors (family, secure self) lose their value, while factors which support regular use, such as negative mood, delinquency, and negative peer groups, gain importance. But independent of the social disintegration, girls are less protected than boys. For girls, protection against the negative peer network associated with consumption may come from a secure self embedded in the productive world of work and school. This has important implications for secondary prevention programs. More research is clearly needed on the social risk for girls of the transition from

Table 5 Path Coefficients of the Model

\begin{tabular}{|c|c|c|c|c|c|}
\hline Paths & $\begin{array}{l}\text { Secure self } \\
\text { Family } \\
\text { relations }\end{array}$ & $\begin{array}{c}\text { Secure self } \\
\text { Peer network }\end{array}$ & $\begin{array}{c}\text { Negative mood } \\
\text { Family } \\
\text { relations }\end{array}$ & $\begin{array}{l}\text { Negative mood } \\
\text { Peer network }\end{array}$ & $\begin{array}{c}\text { Family relation } \\
\text { Delinquency }\end{array}$ \\
\hline \multicolumn{6}{|c|}{ Disintegration } \\
\hline Low & $.32^{* * *}$ & $-.07 \mathrm{~ns}$ & $-.24^{* * *}$ & $.20^{*}$ & $-.19^{* * *}$ \\
\hline Moderate & $.42^{* * *}$ & $-.07 \mathrm{~ns}$ & $-.23^{*}$ & $.07 \mathrm{~ns}$ & $-.08 \mathrm{~ns}$ \\
\hline High & $.21^{*}$ & $-.16^{*}$ & $-.24^{* *}$ & $.21^{* *}$ & $-.11^{*}$ \\
\hline Paths & $\begin{array}{c}\text { Family relation } \\
\text { Cannabis use }\end{array}$ & Peer network & $\begin{array}{l}\text { Peer network } \\
\text { Cannabis use }\end{array}$ & $\begin{array}{l}\text { Delinquency } \\
\text { Cannabis use }\end{array}$ & $\begin{array}{c}\text { Family relation } \\
\text { Peer network }\end{array}$ \\
\hline \multicolumn{6}{|c|}{ Disintegration } \\
\hline Low & $-.09^{*}$ & $.43^{* * *}$ & $.33^{* * *}$ & $.23^{* * *}$ & $-.29^{* * *}$ \\
\hline Moderate & $-.05 \mathrm{~ns}$ & $.37^{* *} 3$ & $.47^{* * *}$ & $-.23^{* * *}$ & $-.22^{*}$ \\
\hline High & $-.09 \mathrm{~ns}$ & $.46^{* * *}$ & $.51^{* * *}$ & $.17^{*}$ & $-.05 \mathrm{~ns}$ \\
\hline
\end{tabular}


school to work. Providing supportive pathways for the development of self-confidence and competence offers a promising direction for secondary prevention.

\section{ACKNOWLEDGMENTS}

We would like to thank the participants in this study. We would also like to thank the Federal Office of Public Health which made this research possible.

\section{REFERENCES}

Andrews, J. A., Tildesley, E., Hops, H., \& Li, F. Z. (2002). The influence of peers on young adult substance use. Health Psychology, 21, 349-357.

Arbuckle, J. L., \& Wothke, W. (1995). AMOS 4.0. Users's guide. Chicago: Small Waters Corporation.

Arénes, J., Janvrin, M.-P., \& Baudier, F. (1998). Baromètre santé jeunes $97 / 98$. Paris: Editions CFES.

Armsden, G. C., \& Greenberg, M. T. (1987). The inventory of parent and peer attachment: Individual differences and their relationship to psychological well-being in adolescence. Journal of Youth and Adolescence, 16, 427-454.

Brook, J. S., Cohen, P., \& Brook, D. W. (1998). Longitudinal study of co-occurring psychiatric disorders and substance use. Journal of the American Academy of Child and Adolescent Psychiatry, 37(3), 322-330.

Brown, R. A., Lewinsohn, P. M., Seeley, J. R., \& Wagner, E. F. (1996). Cigarette smoking, major depression, and other psychiatric disorders among adolescents. Journal of the American Academy of Child and Adolescent Psychiatry, 35(12), 1602-1610.

Burke, J. D., Burke, K. C., \& Rae, D. S. (1994). Increased rates of drug abuse and dependence after onset of mood or anxiety disorders in adolescence. Hospital and Community Psychiatry, 45(5), 451-455.

Comeau, N., Stewart, S. H., \& Loba, P. (2001). The relations of trait anxiety, anxiety sensitivity and sensation seeking to adolescents' motivations for alcohol, cigarette and marijuana use. Addictive Behaviors, 26, 803-825.

Ellickson, P. L., Martino, S. C., \& Collins, R. L. (2004). Marijunana use from adolescence to young adulthood: Multiple development trajectories and their associated outcomes. Health Psychology, 23(3), 299-307.

Fergusson, D., Linskey, M., \& Horwood, J. (1996). Comorbidity between depressive disorders and nicotine dependence in a cohort of 16-year-olds. Archives of General Psychiatry, 53, 1043-1047.

Friedman, A. S., Terras, A., \& Glassman, K. (2000). Family structure versus family relationships for predicting to substance use/abuse and illegal behavior. Journal of Child and Adolescent Substance Abuse, 10(1), 1-16.

Harter, S. (1982). The perceived competence scale of children. Child Development, 53, 87-97.

Hautzinger, M., \& Bailer, M. (1993). ADS: Allgemeine Depressions-Skala. Weinheim: Beltz.

Henry, B., Feehan, M., McGee, R., Stanton, W., Moffitt, T. E., \& Silva, P. (1993). The importance of conduct problems and depressive symptoms in predicting adolescent substance use. Journal of Abnormal Child Psychology, 21(5), 469480 .
Hawkins, J. D., \& Weis, J. G. (1985). The social development model: An integrated approach to delinquency prevention. Journal of Primary Prevention, 6, 73-97.

Hüsler, G., Werlen, E., \& Rehm, J. (2005). The action plan - A new instrument to collect data on interventions in secondary prevention in adolescents. Substance Use and Misuse, 40(6), 761-777.

Hüsler, G., Werlen, E., \& Plancherel, B. (2004). Der Einfluss psychosozialer Faktoren auf den Cannabiskonsum. Suchtmagazin, 3, 221-235.

ISPA. Institut suisse de prévention de l'alcoolisme et autres toxicomanies. (2001). Alcool, tabac et cannabis dans la réalité quotidienne des 12-15 ans. Sélection de résultats issus d'une enquête menée sous l'égide de l'OMS avec le soutien financier de l'OFSP. Lausanne: ISPA.

Jerusalem, M., \& Schwarzer, R. (1999). Allgemeine Selbstwirksamkeit. In Schwarzer, R. \& Jerusalem, M. (Eds.), Skalen zur Erfassung von Lehrer- und Schülermerkmalen (pp. 13). Berlin: Humboldt-Universität.

Kashdan, T. B., Vetter, Ch. J., \& Collins, L. (2005). Substance use in young adults: Associations with personality and gender. Addictive Behavior, 30, 259-269.

Keller, R., Krebs, H., \& Hornung, R. (2002). TabakmonitoringImplementierung eines Forschungs- und Dokumentationssystems. Sozialpsychologie II, Psychologisches Institut der Universität Zürich.

Krebs, H., Keller, R., \& Hornung, R. (2002) Tabakmonitoring - Implementierung eines Forschungs- und Dokumentationssystems. Bericht über das Passivrauchen in der Schweizer Bevölkerung. Im Auftrag des Bundesamtes für Gesundheit, Facheinheit Sucht und Aids. Zürich: Psychologisches Institut der Universität Zürich, Sozial- und Gesundheitspsychologie.

Kline, R. B. (1998). Principles and Practice of Structural Equation Modeling. New York: Guilford Press.

Laux, L., Glanzmann, P., Schaffner, P., \& Spielberger, C. D. (1981). Das State-Trait-Angstinventar (STAI). Weinheim: Beltz.

Loeber, R., Stouthamer-Loeber, M., Van Kammen, W., Farrington, D. (1989). Development of a new measure of selfreported antisocial behaviour for young children: prevalence and reliability. In Klein, M. (Ed.) Cross-National Research on Alcohol and Other Drugs; Alcohol and Other Drug Use Among Students in 26 European Countries. Stockholm: Modin Tryck.

Macleod, J., Oakes, R., Copello, A., Crome, I., Egger, M., Hickman, M., Oppenkowski, T., Stokes-Lampard, H., \& Smith, G. D. (2004). Psychological and social sequelae of cannabis and other illicit drug use by young people: A systematic review of longitudinal, general population studies. Lancet, 365, 1579-1588.

McCuller, W. J., Sussman, S., Dent, C. W., \& Teran, L. (2001). Concurrent prediction of drug use among high-risk youth. Addictive Behaviors, 26, 137-142.

Michel, G., Carton, S., Perez-Diaz, F., Mouren-Siméoni, M. C., \& Jouvent, R. (1998). Symptomatologie dépressive et consommation de substances psycho-actives chez des lycéens. Neuropsychiatrie de l'Enfance et de l'Adolescence, 46(10-11), 531-536.

Narring, F., Tschumper, A., Michaud, P.-A., Vanetta, F., Meyer, R., Wydler, H., Vuille, J.-C., Paccaud, F., \& Gutzwiler, F. (1994). La santé des adolescents en Suisse: Rapport d'une enquête nationale sur la santé et les styles de vie des 15-20 ans. Lausanne: IUMSP.

Petraitis, J., Flay, B. R., \& Miller, T. Q. (1995). Reviewing theories of adolescent substance use: Organizing pieces in the puzzle. Psychological Bulletin, 117(1), 67-86.

Poikolainen, K., Tuulio-Henriksson, A., Aalto-Setala, T., Marttunen, M., Anttila, T., \& Lonnqvist, J. (2001). Correlates of initiation to cannabis use: A 5-year follow-up of 
15-19-year-old adolescents. Drug and Alcohol Dependence, 62(3), 175-180.

SAMHSA. (1999). The relationship between mental health and substance use among and adolescents. Office of Applied Studies. U.S. Department of Health and Human Services Administration. Retrieved Octobre 8, 2003, from Substance Abuse and Mental Health Services Administration (SAMHSA) Web site: http://www.samhsa.gov/oas/NHSDA/A-9/comorb3c. htm\#TopOfPage.

Szapocznik, J., \& Coatsworth, J. D. (1999). A ecodevelopmental framework for organzining the influences on drug abuse: A developmental model of risk and protection. In Glantz, M., \& Hartel, C. R. (Eds.) Drug abuse: Origins and interventions (pp 331-366). Washington DC: American Psychological Association.

Sobeck, J., Abbey, A., Agius, E., Clinton, M., \& Harrison, K. (2000). Predicting early adolescent substance use: Do risk factors differ depending on age of onset? Journal of Substance Abuse, 11, 89-102.

Supple, A. J., Aquilino, W. S., \& Wright, D. L. (1999). Collecting sensitive self-Report data with laptop computers: Im- pact on the response tendencies of adolescents in a home interview. Journal of Research on Adolescence, 9(4), 467488

Swaim, R. C., Scott, C. B., \& Chavez, E. L. (1998). Structural equation socialization model of substance use among MexicanAmerican and white Non-Hispanic school dropouts. Journal of Adolescent Health, 23, 128-138.

Von Sydow, K., Lieb, R., Pfister, H., Höfler, M., \& Wittchen, H. U. (2002). What predicts incident use of cannabis and progression to abuse and dependence? A 4-year prospective examination of risk factors in a community sample of adolescents and young adults. Drug and Alcohol Dependence, 68, 4964.

Wills, T. A., \& Vaughan, R. (1989). Social support and substance use in early adolescence. Journal of Behavioral Medicine, 12(4), 321-339.

Wills, T. A., Vaccaro, D., \& McNamara, G. (1994). Novelty seeking, risk taking, and related constructs as predictors of adolescent substance use: an application of Cloninger's theory. Journal of Substance Abuse, 6(1), 120. 